\title{
Estrutura e dinâmica em uma floresta densa de terra firme, Sudeste do Amapá, Brasil
}

\author{
Ronaldo Oliveira dos SANTOS ${ }^{1 *}$, Rubiene Neto SOARES ${ }^{1}$, Bruno Costa do ROSÁRIO², \\ Robson Borges de LIMA ${ }^{1}$, Jadson Coelho de ABREU ${ }^{1}$ \\ ${ }^{1}$ Departamento de Engenharia Florestal, Universidade do Estado do Amapá, Macapá, AP, Brasil. \\ ${ }^{2}$ Programa de Pós-Graduação em Ciências Tropicais, Instituto Nacional de Pesquisas da Amazônia, Manaus, AM, Brasil. \\ *E-mail: santos.ueap@hotmail.com
}

Recebido em outubro/2017; Aceito em julho/2018.

\begin{abstract}
RESUMO: O objetivo deste estudo foi analisar a variação da estrutura diamétrica de uma comunidade arbórea em floresta densa de terra firme e dos principais grupos de espécies de estágios iniciais e tardios de sucessão, bem como caracterizar a estrutura vertical da floresta. Em 2016, foram inventariadas todas as árvores com DAP $\geq 10 \mathrm{~cm}$ e mensuradas suas alturas. Em 2017, as árvores foram reamostradas. A estrutura diamétrica foi analisada por meio do quociente "q" De Liocourt para: a comunidade, principais espécies de maior VI e os grupos ecológicos (GE). A análise da estrutura vertical da vegetação foi feita pela distribuição do número de árvores nos estratos, utilizando-se três métodos: (I) - Sanquetta (1995), (II) - Souza (1990), e (III) - Souza et al. (2003). A estrutura diamétrica da comunidade e dos GE no período avaliado foi caracterizada por árvores de pequeno porte nas menores classes de diâmetro. O Método II não trouxe bons resultados sobre o comportamento das espécies no estrato médio por apresentar fortes tendências em concentrar um maior número de indivíduos nesse estrato. Os resultados da estrutura altimétrica e diamétrica demonstraram indicativos que a exploração antrópica no passado alterou a estrutura da floresta.
\end{abstract}

Palavras-chave: espécies amazônicas, "q” De Licocourt, estratificação, incremento.

\section{Structure and dynamics in a dense of terra firme forest, southeast of Amapá, Brazil}

\begin{abstract}
The study aimed to analyze the variation of the diameter structure of a arboreal community in a dense terra firme forest and the main groups of species of early and late stages of succession, as well as characterize the vertical structure of the forest. In 2016, all trees with $\mathrm{DBH} \geq 10 \mathrm{~cm}$ were inventoried and their heights measured indirectly. In 2017, the trees were re-measured. The diametric structure was analyzed using the "q" De Liocourt quotient for: the community, major species of higher (VI) and ecological groups (EG). The analysis of the vertical structure of the vegetation was made by the distribution of the number of trees in the strata, using three methods: (I) - Sanquetta (1995), (II) - Souza (1990), and (III) - Souza et al. (2003). The diametric structure of the community and the EG during the period evaluated was characterized by small trees in the smallest diameter classes. Method II did not bring good results on the behavior of the species in the middle stratum because it presents strong tendencies to concentrate a greater number of individuals in this stratum. The results of the altimetric and diametric structure have demonstrated that antropic exploration in the past has altered the structure of the forest.
\end{abstract}

Keywords: amazonian species, “q” De Licocourt, stratification, increment.

\section{INTRODUÇÃO}

A expressiva maioria dos trabalhos com o enfoque na análise da estrutura em florestas nativas do Brasil, ainda considera apenas uma só abordagem de análise, ora estuda a estrutura horizontal (CARVALHO; NASCIMENTO, 2009; SILVA et al., 2016) ora a estrutura vertical (SOUZA; SOUZA, 2004; CURTO et al., 2013), mas não ambos concomitantemente em suas totalidades (SOUZA et al., 2006; SANTOS et al., 2017), o que consequentemente não tem fornecido informações significativas para o planejamento do Manejo Silvicultural adequados para uma dada região.

Nesse contexto, estudos sobre a estrutura horizontal em particular no tocante a distribuição diamétrica é uma abordagem fundamental para nortear tomadas de decisões relacionadas ao manejo, conservação e restauração dos estandes florestais. Uma vez que, o conhecimento sobre a estrutura diamétrica é de fundamental importância, tanto em nível de comunidade quanto de povoamento, pois sua mensuração ajuda inferir sobre o grau de conservação e o estágio que se encontra as florestas naturais visando conduzir a uma estrutura balanceada dos diâmetros das espécies, bem como associar tal informação aos estudos de dinâmica florestal (SANTOS et al., 2016).

A importância da avaliação da distribuição diamétrica em inventários contínuos em florestas tropicais está na possibilidade de ter o conhecimento sobre ingresso, mortalidade e histórico de desenvolvimento das espécies arbóreas (REIS et al. 2014), bem como de avaliar a intensidade de perturbações seja ela de ordem antrópica ou natural que ocorreram na comunidade florestal. Embora muito empregada sob o ponto de vista da produção florestal (SCOLFORO et al., 1997; SOUZA et al., 2006), a distribuição diamétrica pode fornecer além do estoque de madeira disponível para manejo, a descrição sobre a forma atual de sucessão da vegetação, o estoque de carbono por classe de diâmetro, e o comportamento ecológico das espécies em termos de incremento médio anual em função dos grupos ecológicos existente na fitocenose. 
Uma abordagem importante e pouca adotada atualmente nos estudos acerca da estrutura diamétrica de comunidade florestais no Brasil é a utilização do quociente “q" De Liocourt (1898). Esta abordagem busca verificar se a distribuição dos diâmetros dos indivíduos de uma dada comunidade segue uma estrutura balanceada, isto é, se houver uma razão constante das frequências desses indivíduos entre as classes, sugere-se que a taxa de recrutamento é similar à taxa de mortalidade, e que a distribuição pode ser considerada regular ou equilibrada (FELFILI; RESENDE, 2003). Nessa perspectiva, alguns trabalhos salientam que com base no resultado da distribuição diamétrica a partir do quociente " $q$ ", pode-se inferir sobre o estado de perturbação das florestas por meio da identificação de classes em que existe déficit ou superávit de árvores (SCOLFORO et al., 1997; ALVES-JÚNIOR et al., 2010).

O diâmetro por si só define padrões de uso da floresta (MACHADO; FIGUEIREDO-FILHO, 2014). Contudo, a técnica da distribuição diamétrica não garante por si só total compreensão no que concerne abrangência de informações acerca do comportamento estrutural da vegetação (CURTO et al., 2013). Por essa razão, se faz necessário adotar simultaneamente outros tipos de análises estruturais, destacando-se a estrutura vertical, como uma alternativa de agregar informações relevantes aos resultados produzidos pela distribuição diamétrica. Vários estudos (SANQUETTA, 1995; SOUZA, 1990; SOUZA et al., 2003; CURTO et al., 2013) têm demonstrado a importância da caracterização da estrutura vertical em florestas tropicais seja para fins de manejo e/ou conservação, apesar disso, ainda são incipientes os trabalhos que buscam analisar a floresta na ótica da sua estrutura vertical e horizontal concomitantemente.

A avaliação do perfil vertical das árvores de um povoamento é de grande interesse para o manejo florestal, tendo em vista que a variável altura é fundamental para as estimativas de volume e da produtividade de determinado sítio. Soma-se a isto o fato que quando associada aos conhecimentos da estrutura diamétrica à análise vertical fornece subsídios para compreensão do comportamento ecológico das espécies e orienta para o ordenamento correto de práticas silviculturais visando à sobrevivência das árvores que estejam ameaçadas na área. Desta forma, segundo Sanquetta (1995), a análise dos diferentes estratos em altura (inferior, médio e superior) que uma floresta pode apresentar, acaba revelando importantes informações para o entendimento das características de cada espécie, dando embasamento para formulação das estratégias de crescimento e sobrevivência.

Parece ser consenso que toda a dinâmica da floresta tropical é dependente da formação de clareiras oriundas de queda de árvores ou de parte delas. Esses distúrbios, portanto, são o principal fator responsável pela composição florística e crescimento da vegetação na floresta tropical (JARDIM, 1990).Assim, o estudo da dinâmica pode possibilitar o entendimento dos processos por meio dos quais ocorrem as mudanças, em níveis de espécies e para a floresta como um todo (FIGUEIREDO-FILHO et al., 2010).

Partindo da premissa que as ações antrópicas no passado, somadas aos distúrbios naturais do presente, são fatores que podem determinar possíveis alterações da estrutura horizontal e vertical da vegetação da área do presente estudo. Assim, este trabalho objetivou analisar a variação da estrutura diamétrica da comunidade e dos principais grupos de espécies arbóreas de estágios iniciais e tardios de sucessão, bem como caracterizar a estrutura vertical da floresta.

\section{MATERIAL E MÉTODOS}

\section{1. Área de estudo}

O estudo foi realizado em uma propriedade particular denominada de Sítio São Miguel da Areia Branca (Figura 1), na localidade de Cariobal pertencente ao município de Macapá-AP. O clima da região é classificado como Amw', segundo Köppen, consistindo em uma estação chuvosa de novembro a junho e uma estação seca de julho a outubro (IEPA, 2008). A temperatura média para todo o Estado é em torno de $25^{\circ} \mathrm{C}$, com máxima de $\left(32^{\circ} \mathrm{C}\right)$ e mínima $\left(22^{\circ} \mathrm{C}\right)$, e a precipitação média anual na região é de $2.284 \mathrm{~mm}$ (IEPA, 2008).

O relevo apresenta predominância de feições planas de pequena altitude, sendo que a área da propriedade é de 78 ha, na qual $7 \%$ desse total já são ambientes alterados por ações antrópicas, como por exemplo, conversão da vegetação em pasto para atividade bovina e extração de madeira para fins domésticos (estacas e mourões). A tipologia florestal é caracterizada em áreas de floresta ombrófila densa de terra firme, cujo dossel está entre 20 e $35 \mathrm{~m}$ de altura, possuindo espécies emergentes que podem atingir até $40 \mathrm{~m}$ de altura (IEPA, 2008).

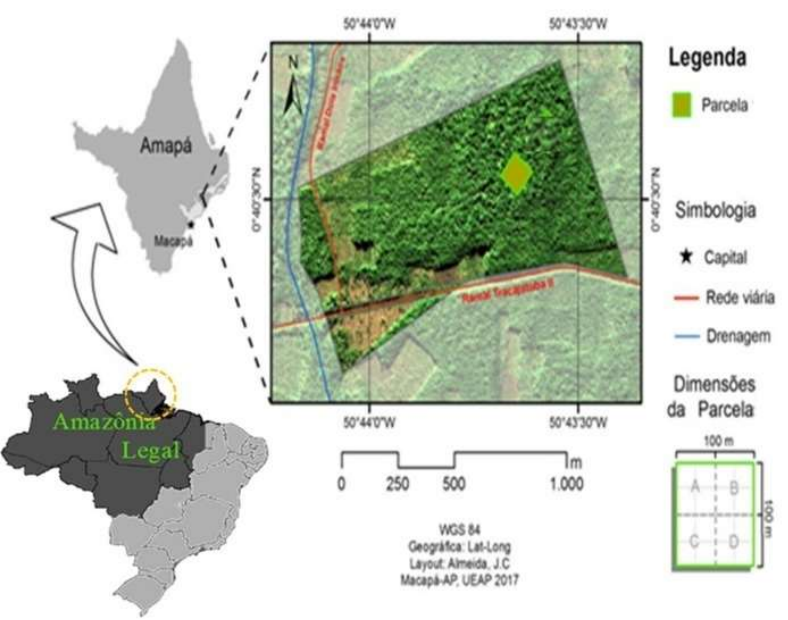

Figura 1. Descrição da área de estudo na localidade de Cariobal no município de Macapá, Amapá, Brasil.

Figure 1. Description of the study area in the locality of Cariobal in the municipality of Macapá, Amapá, Brazil.

\subsection{Processo de amostragem}

Para análise da vegetação foi empregado o método de parcelas permanentes de 1 ha com o propósito de avaliar a dinâmica da distribuição diamétrica ao longo do tempo. Os dados das variáveis dendrométricas foram coletados em abril de 2016 e março de 2017 em 40 subunidades amostrais de 250 $\mathrm{m}^{2}(10 \times 25 \mathrm{~m})$ alocadas em campo.

O inventário florestal contínuo teve início em 2016, com a realização da primeira campanha a qual foi realizada o levantamento florístico e fitossociológico das espécies arbóreas com DAP (diâmetro à altura do peito) $\geq 10 \mathrm{~cm}$. Dentro de cada subparcela foram obtidas as alturas comercial e total das espécies com auxílio de hipsômetro True Pulse $360^{\circ}$, e dos diâmetros à altura do peito (DAP) utilizando trena de bolso.

No ano subsequente, foi realizada a segunda campanha, na tentativa de monitorar os possíveis impactos sobre a flora local, sendo que todas as árvores vivas avaliadas na primeira campanha foram remedidas, sempre no mesmo lugar chamado 
"ponto de medição", marcado com uma faixa de tinta a óleo vermelha localizado a $1,30 \mathrm{~m}$ do solo.

\subsection{Análise dos dados}

Com os dados dos monitoramentos de 2016 e 2017 das espécies arbóreas realizou-se à análise da estrutura diamétrica por meio de histogramas de frequências, com intervalos de classes determinados a partir da fórmula de Spiegel citada por Felfili; Resende (2003). Esta análise foi realizada considerando a comunidade arbórea e para as populações das espécies mais representativas com base no índice de valor de importância (VI) encontrado na área e no coeficiente de determinação $\left(\mathrm{R}^{2}\right)$ maior ou igual a $50 \%$ pela análise de regressão. A espécie que não obedeceu aos critérios préfixados (apresentar coeficiente de determinação com valor mínimo de $50 \%$ e indivíduos presentes no mínimo em quatro classes diamétricas) foi substituída pela espécie consecutiva, de acordo com a ordem de VI, conforme a Tabela 1.

Tabela 1. Parâmetros analisados das espécies de maior VI, em ordem decrescente, encontradas na floresta de terra firme no município de Macapá, Amapá, Brasil.

Table 1. Parameters analyzed of the species of higher VI, in decreasing order, found in the terra firme forest in the municipality of Macapá, Amapá, Brazil.

\begin{tabular}{|c|c|c|c|c|c|c|c|}
\hline \multirow{2}{*}{ Espécies } & \multirow{2}{*}{ GE } & \multicolumn{2}{|c|}{$\mathrm{Ni}$} & \multicolumn{2}{|c|}{ VI } & \multicolumn{2}{|c|}{$\mathrm{R}^{2}(\%)$} \\
\hline & & 2016 & 2017 & 2016 & 2017 & 2016 & 2017 \\
\hline Ecclinusa guianensis Eyma & St & 50,00 & 50,00 & 33,73 & 34,94 & 82,73 & 93,43 \\
\hline Cordia tetrandra Aubl. & St & 40,00 & 39,00 & 21,80 & 22,18 & 79,37 & 82,20 \\
\hline Byrsonima crispa Juss. & St & 24,00 & 24,00 & 18,28 & 18,41 & 34,40 & 35,10 \\
\hline Protium decandrum (Aubl.) Marchand & St & 26,00 & 26,00 & 16,89 & 17,04 & 58,25 & 64,51 \\
\hline Rinorea racemosa (Mart.) Kuntze & $\mathrm{Si}$ & 24,00 & 24,00 & 14,44 & 14,92 & 69,73 & 54,01 \\
\hline Eugenia muricata DC. & $\mathrm{Pi}$ & 15,00 & 15,00 & 13,82 & 13,83 & 24,83 & 24,85 \\
\hline Parahancornia fasciculata (Poir.) Benoist & St & 13,00 & 13,00 & 13,18 & 13,20 & 34,38 & 34,40 \\
\hline Osteophloeum platyspermum (Spruceex A. DC.) & St & 16,00 & 16,00 & 10,95 & 11,06 & 43,11 & 43,39 \\
\hline Jacaranda copaia (Aubl.) D. Don & $\mathrm{Pi}$ & 11,00 & 11,00 & 9,79 & 9,84 & 10,21 & 10,22 \\
\hline
\end{tabular}

Legenda: GE - Grupo ecológico; Ni - Número de indivíduos; e R² - Coeficiente de determinação.

Foi considerado também nesta análise o conjunto das espécies pertencentes aos grupos ecológicos, sendo que as mesmas foram classificadas com base no trabalho de Budowski (1965) e apoiando-se na classificação proposta por Amaral et al. (2009) e Oliveira et al. (2005) que adotaram a divisão das espécies em três grupos ecológicos, a saber: pioneiras, secundárias iniciais e secundárias tardias. Após a determinação das classes diamétricas, foram realizadas as estimativas de frequências por classe de diâmetro. Para tanto, foi utilizada a função de Meyer (1952) tipo I em sua forma linearizada (Equação 1), baseada na teoria de DeLiocourt na qual descreve a distribuição balanceada dos diâmetros como uma função exponencial negativa conforme descrita por Campos et al. (1983):

$$
\operatorname{Ln}\left(Y_{i}\right)=\beta_{0}+\beta_{1} \cdot X_{i}+\varepsilon i \quad(\text { Equação } 1)
$$

em que: $\operatorname{Ln}(\mathrm{Yi})=$ logaritmo natural do número de indivíduos por hectare por classe de diâmetro; $\mathrm{Xi}=$ centro de classe de diâmetro; $\beta 0$ e $\beta 1=$ parâmetros dos ajustes; $\varepsilon=$ erro aleatório.

De modo a viabilizar o cálculo quando da inexistência de indivíduos em alguma classe, foi somado o número 1 como constante a todas as classes conforme procedimento adotado por Alves-Júnior et al. (2010) e Lima et al. (2013). Com base na função de distribuição ajustada tanto para a comunidade quanto para as principais populações da floresta, foi obtido o quociente "q" intrínseco da vegetação por meio da Equação (2):

$$
q=\frac{e^{\left(\beta_{0}+\beta_{1} \cdot X_{j}\right)}}{e^{\left(\beta_{0}+\beta_{1} \cdot X_{j+1}\right)}} \quad \text { (Equação 2) }
$$

em que: $\mathrm{q}=$ constante de De Liocourt; $\mathrm{Xj}=$ diâmetro correspondente ao centro da j-ésima classe de DAP; $\mathrm{Xj}+1$ = diâmetro correspondente ao centro da jésima classe de dap imediatamente acima.

Também foi considerado como objeto de análise o crescimento em diâmetro e área basal das espécies no que tange o período avaliado. Assim, o incremento periódico anual em diâmetro $\left(\mathrm{IPA}_{\mathrm{d}}\right)$ e em área basal $\left(\mathrm{IPA}_{\mathrm{G}}\right)$ foram analisados em nível de grupo ecológico, bem como foi avaliada também a taxa de mortalidade (M\%) e ingresso ( $\mathrm{In} \%)$ para a floresta adotando os mesmos procedimentos analíticos do trabalho de Cubas et al. (2016).Para o cálculo da mortalidade foram considerados os seguintes estados: árvore morta em pé, árvore morta caída ou quebrada por ação de agentes naturais.

Para a caracterização da estrutura vertical da vegetação foram utilizados três métodos de análise, a saber: Sanquetta (1995), Souza (1990), e Souza et al. (2003). No método de Sanquetta (1995) denominado Diagrama h-M, a definição dos estratos é realizada com base em várias etapas, cuja etapa final consiste em analisar as mudanças de diferenças de "picos" no gráfico, sendo que estas mudanças representam os limites entre os estratos. Em síntese, podemos caracterizar este método da seguinte maneira: i) primeiramente é calculado o número de classes altimétricas, para o presente estudo, foram utilizadas 11 classes com intervalo de dois metros de altura; ii) posteriormente as frequências dos indivíduos são organizados em ordem decrescente de centro de classe $(\mathrm{CCH})$; iii) em seguida é calculado as frequências acumulativas por cada classe (N); iv) e por fim é gerado o valor de $\mathrm{M}$ - (representa a média cumulativa parcial da atura a partir de maior valor de h), sendo obtido pela razão $=(\mathrm{CCH} / \mathrm{N})$.

Contudo, a determinação dos estratos da floresta é feita visualmente por meio da plotagem de um gráfico cartesiano, em que no eixo das abscissas é constituído pelos valores de $\mathrm{M}$, e no eixo das ordenadas pelos valores de $\mathrm{CCH}$.

Para o método de Souza (1990), a estratificação da floresta foi classificada por meio dos valores da estatística paramétrica dos dados de altura, com destaque para a média aritmética e desvio padrão. De posse dessas estatísticas os estratos foram definidos pelas seguintes expressões: estrato inferior (EI) árvores com $h i<(\bar{h}-s)$; estrato médio $(\mathrm{EM})$ - árvores com $(\bar{h}-s) \leq h i<(\bar{h}+s)$; e estrato superior (ES) - árvores 
com $h i \geq(\bar{h}+s)$. Em seguida, foi confeccionado um gráfico do tipo boxplot para visualização dos estratros. Nesse caso: $\bar{h}$ = média aritmética das alturas totais (hi) dos indivíduos amostrados; e $\mathrm{s}=$ desvio padrão das alturas totais (hi) dos indivíduos amostrados.

Para o método de Souza et al. (2003) foi adotada a análise multivariada para estratificação, a qual agrupou-se os dados de altura total das árvores em uma matriz de dados de classes altimétricas, em que cada variável foi utilizada como input para posterior análise de agrupamento e discriminante. Para esta análise foi empregado os mesmos procedimentos utilizados nos trabalhos de Souza; Souza (2004) e Curto et al. (2013), com a exceção da amplitude entre as classes altimétricas, sendo que na atual pesquisa considerou-se uma amplitude de $2 \mathrm{~m}$, e nos trabalhos supracitados foram adotados $1 \mathrm{~m}$.

Com o propósito de comparar os métodos visando diagnosticar qual deles descreveu de forma mais satisfatória os estratos da vegetação, foi calculado o coeficiente de variação (C.V) para o conjunto de dados das alturas e dos diâmetros dentro dos estratos para cada procedimento utilizado. Assim, a eficiência do método foi satisfatória quando houve a diminuição do C.V dentro do estrato após análise, conforme procedimento utilizado por Amaral (2011). Todas as análises empregadas foram realizadas utilizando software R (R CORE TEAM, 2015).

\section{RESULTADOS}

3.1. Estrutura diamétrica, mortalidade e ingresso

Em 2016 foram registrados 400 indivíduos, pertencentes a 24 famílias, 48 gêneros e 59 espécies. Em 2017, foram observadas poucas mudanças na estrutura da vegetação, sendo evidenciada alteração no número de árvores computadas. A mortalidade registrada no período avaliado foi de 9 indivíduos.ha ${ }^{-1}$. ano $^{-1}$, com taxa de $2,25 \%$. O ingresso encontrado na área de estudo foi de 7 indivíduos.ha ${ }^{-1}$.ano ${ }^{-1}$, com taxa de $1,75 \%$.
A estrutura diamétrica da comunidade e para os grupos sucessionais, tanto no ano de 2016 como em 2017 caracterizam-se por árvores de pequeno porte nas menores classes de diâmetro (Figura 2), confirmando a curva de distribuição decrescente de florestas tropicais.

Considerando os dados de todos os indivíduos da comunidade foi observado problemas de regeneração, em razão dos valores dos quocientes "q1 a q5" De Liocourt entre as classes serem maiores do que os do "q" médio calculado em 2016 e 2017 (Tabela 2).

Quanto às avaliações da distribuição diamétrica em nível de povoamento, foi observado que a maioria das espécies selecionadas com base no coeficiente de determinação $\left(\mathrm{R}^{2} \geq\right.$ $50 \%$ ) demonstraram o mesmo comportamento de distribuição que a comunidade geral, ou seja, na forma de "J" invertido (Figura 3), como algumas exceções para Protium decandrum e Rinorea racemosa.

Os quocientes "q2, q5 e q6" para Ecclinusa guianensis, demonstraram ausência de problemas de regeneração na área no intervalo avaliado. Todavia, é verificado que algumas classes permaneceram acima dos valores de q médio (Tabela 2), sugerindo distribuição diamétrica desbalanceada. Este efeito pode ser atribuído aos baixos valores das frequências por classe de diâmetro para cada espécie individualmente, sendo que a maioria delas concentraram-se nas menores classes diamétricas 1, 2 e $3-($ DAP $<26 \mathrm{~cm})$ (Figura 3$)$.

\subsection{Estrutura vertical}

A estratificação vertical da floresta demonstrou que a comunidade é composta por três grupos principais de classe de altura total (inferior, médio e superior), sendo que a altura média dos indivíduos amostrados foi de $16,33 \mathrm{~m}$. Logo, pelas disposições das árvores no espaço (floresta), verificou-se que a maioria encontra-se no perfil médio de altura, isto é, a faixa que corresponde às alturas entre 12 a $20 \mathrm{~m}$ (Figura 4), com a dominância de $71 \%$ dos indivíduos.

Tabela 2. Quociente "q" de DeLiocourt da comunidade e das populações sucessionais estudadas, relacionado com a distribuição diamétrica para o ano de 2016 e 2017 da floresta densa de terra firme no município de Macapá, Amapá, Brasil.

Table 2. De Liocourt's "q" quotient of the community and of the succession populations studied related with the 2016 and 2017 diametric distribution of the dense terra firme forest in the municipality of Macapá, Amapá, Brazil.

\begin{tabular}{|c|c|c|c|c|c|c|c|c|c|c|c|}
\hline \multicolumn{12}{|c|}{2016} \\
\hline & $\mathrm{q} 1$ & $\mathrm{q} 2$ & $\mathrm{q} 3$ & $q 4$ & q5 & q6 & q7 & q8 & q9 & $\mathrm{q} 10$ & qmédia \\
\hline Comunidade total & 2,14 & 2,59 & 2,41 & 2,43 & 7,00 & 1,00 & 1,00 & 1,00 & 1,00 & 0,00 & 2,06 \\
\hline Pioneiras & 1,38 & 0,67 & 2,00 & 0,67 & 9,00 & 0,50 & 0,04 & - & - & - & 2,04 \\
\hline Secundárias iniciais & 1,55 & 1,38 & 8,00 & 1,00 & 1,00 & 0,03 & - & - & - & - & 2,16 \\
\hline Secundárias tardias & 1,83 & 1,53 & 1,31 & 2,77 & 1,86 & 3,50 & 0,50 & 4,00 & 0,00 & $=$ & 1,92 \\
\hline Ecclinusa guianensis & 1,70 & 0,83 & 2,00 & 3,00 & 0,67 & 0,06 & - & - & - & - & 1,48 \\
\hline Cordia tetrandra & 2,56 & 3,00 & 1,50 & 2,00 & 0,50 & 0,05 & - & - & - & - & 1,91 \\
\hline Protium decandrum & 2,33 & 0,38 & 1,60 & 2,50 & 2,00 & 0,04 & - & - & - & - & 1,47 \\
\hline Rinorea racemosa & 1,40 & 1,00 & 2,50 & 0,50 & 4,00 & 0,04 & - & - & - & - & 1,57 \\
\hline \multicolumn{12}{|c|}{2017} \\
\hline Comunidade total & 2,13 & 2,40 & 2,53 & 2,43 & 7,00 & 1,00 & 1,00 & 1,00 & 1,00 & 0,00 & 2,05 \\
\hline Pioneiras & 1,43 & 0,54 & 2,17 & 0,67 & 9,00 & 0,50 & 0,04 & - & - & - & 2,05 \\
\hline Secundárias iniciais & 1,33 & 1,71 & 3,50 & 2,00 & 1,00 & 0,03 & - & - & - & - & 1,60 \\
\hline Secundárias tardias & 1,79 & 1,40 & 1,47 & 2,43 & 2,00 & 2,33 & 1,00 & 1,50 & 0,01 & - & 1,55 \\
\hline Ecclinusa guianensis & 1,45 & 1,00 & 1,57 & 3,50 & 0,67 & 0,06 & - & - & - & - & 1,38 \\
\hline Cordia tetrandra & 3,14 & 1,75 & 1,33 & 3,00 & 0,50 & 0,05 & - & - & - & - & 1,63 \\
\hline Protium decandrum & 1,50 & 0,57 & 1,17 & 3,00 & 2,00 & 0,04 & - & - & - & - & 1,38 \\
\hline Rinorea racemosa & 0,71 & 1,40 & 2,50 & 1,00 & 0,67 & 0,13 & - & - & - & - & 1,07 \\
\hline
\end{tabular}



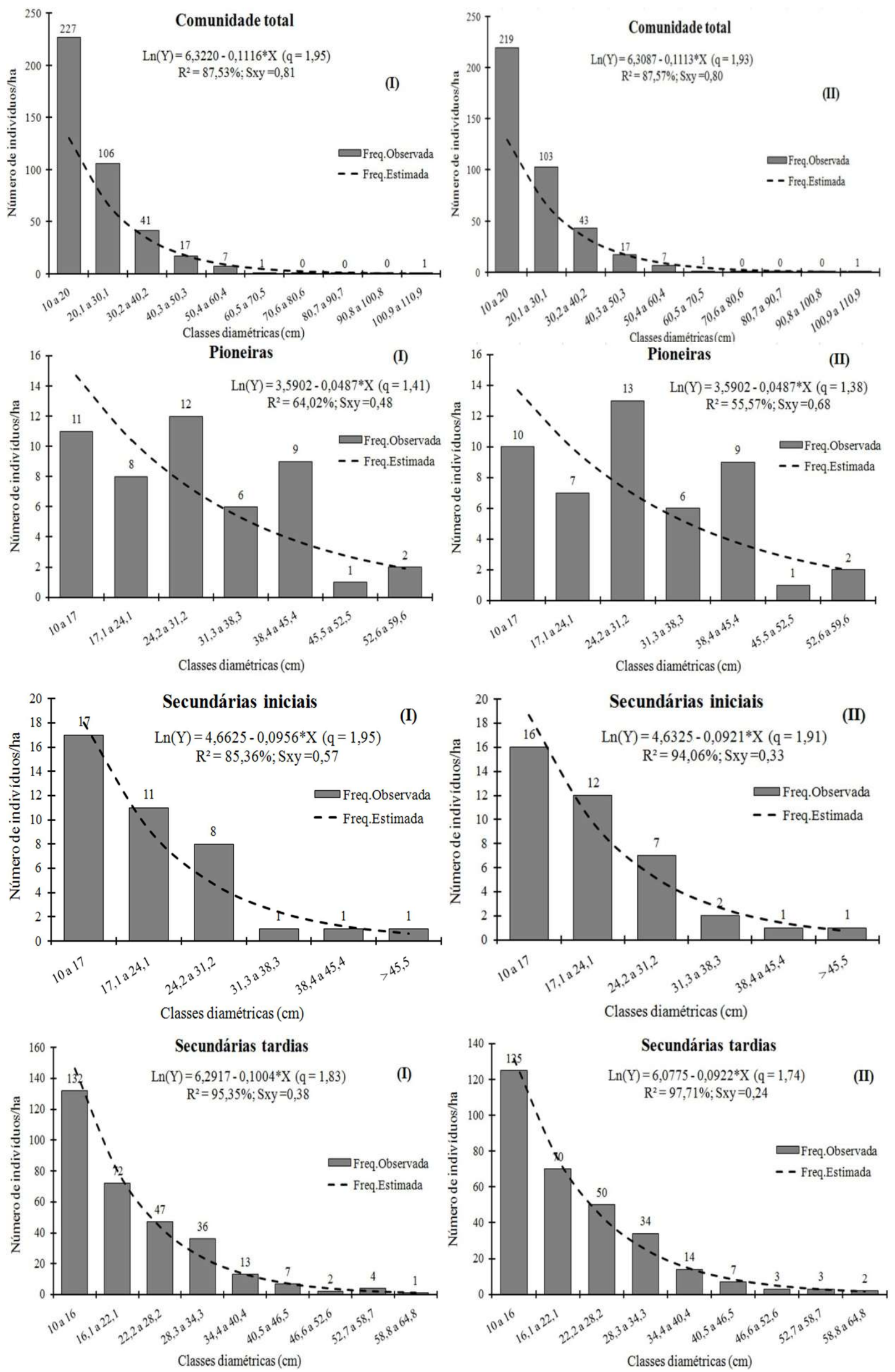

Figura 2. Distribuição diamétrica em 2016 - (I) e 2017 - (II) da comunidade e separadamente por classificação sucessional das espécies arbóreas da área amostrada em floresta densa de terra firme no município de Macapá, Amapá, Brasil.

Figure 2. Diametric distribution in 2016 - (I) and 2017 - (II) of the community and separately by successional classification of arboreal species of the area sampled in dense terra firme forest in the municipality of Macapá, Amapá, Brazil. 
Santos et al.
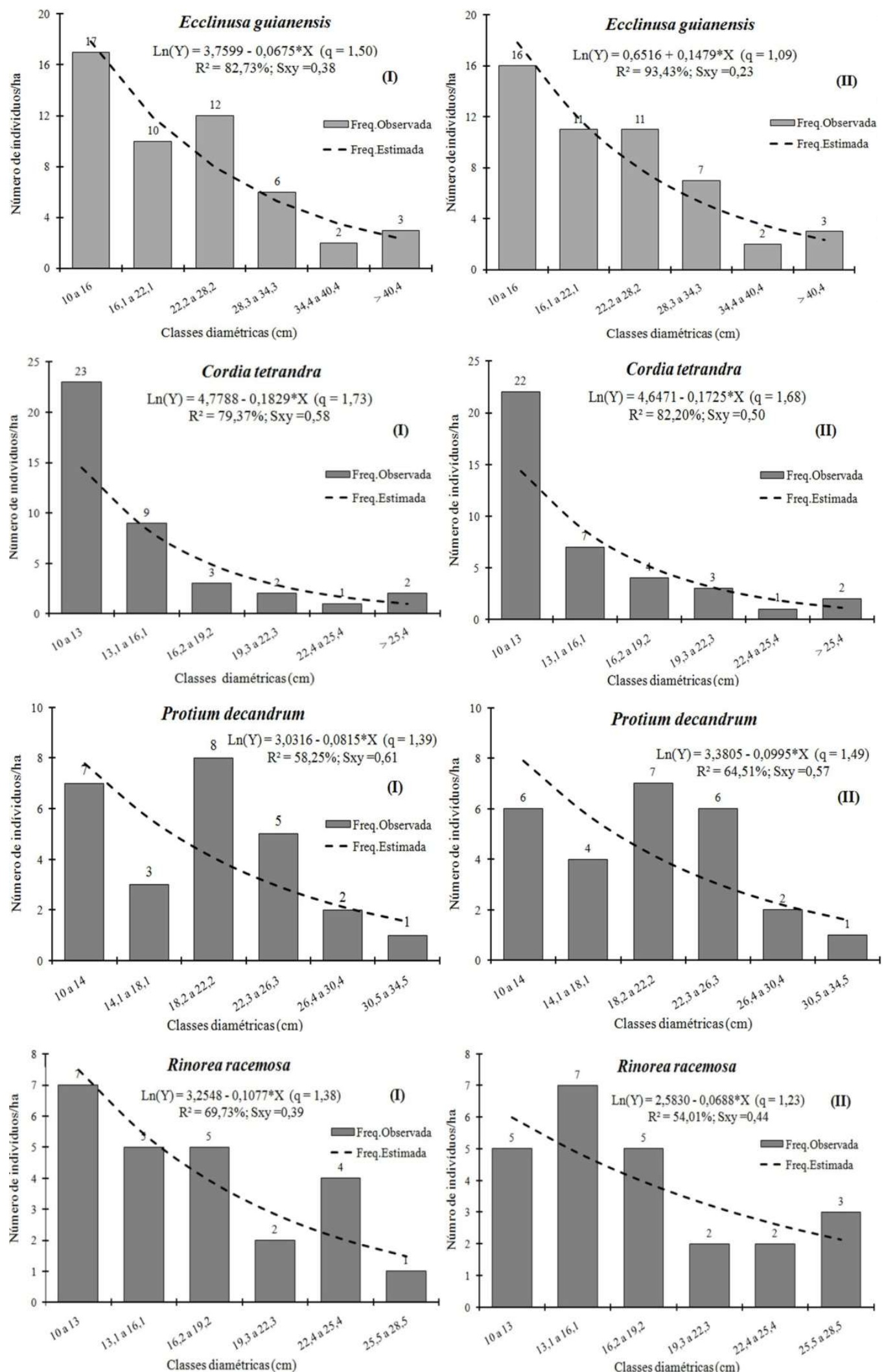

Figura 3. Distribuição diamétrica das quatro espécies selecionadas com coeficiente de determinação $\left(\mathrm{R}^{2}\right) \geq 50 \%$; amostradas em floresta densa de terra firme no município de Macapá, Amapá, Brasil.

Figure 3. Diametric distribution of the four selected species with determination coefficient $\left(\mathrm{R}^{2}\right) \geq 50 \%$; sampled in dense terra firme forest in the municipality of Macapá, Amapá, Brazil. 


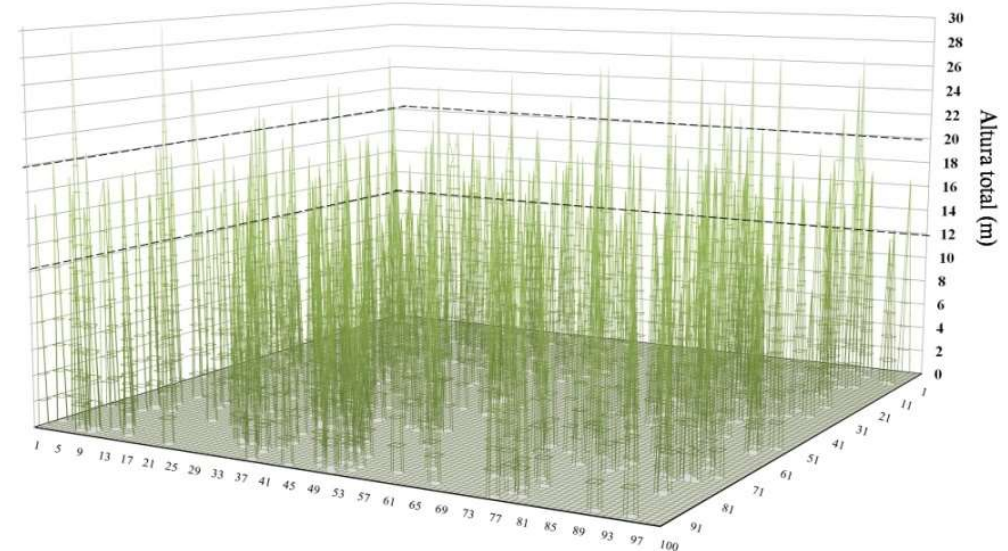

Figura 4. Representação do perfil vertical dos estratos da área de floresta de terra firme analisada. Figure 4. Representation of the vertical profile of the strata of the terra firme forest area analyzed.

No que tange as técnicas empregadas para caracterizar a estrutura vertical da vegetação, observamos que ambas classificaram este parâmetro em três estratos de altura total, a saber: estrato inferior (I), médio (II) e superior (III). No método baseado em Sanqueta (1995) - (Figura 5A), verificouse que os estratos são determinados pelas diferenças de "picos" no gráfico, isto é, por meio da variação dos valores contidos nos dois eixos. Deste modo, o estrato inferior é caracterizado por indivíduos cujos valores de altura não ultrapassaram $20 \mathrm{~m}$. Já o segundo estrato é formado por árvores com dimensões entre 20,1 a 25 metros de altura, e o estrato três é composto pelo conjunto de plantas que possui altura entre 25,1 e $30 \mathrm{~m}$.

Com base no método de Sanquetta, a maior frequência dos indivíduos (344) foram agrupadas no estrato inferior de altura $(\mathrm{Ht} \leq 20 \mathrm{~m})$. As espécies que mais se destacaram nesse perfil vertical foram: Ecclinusa guianensis correspondendo com $14,53 \%$ do total de indivíduos presentes no estrato, seguida de Cordia tetrandra com 11,62\%, Protium decandrum com $7,55 \%$, Byrsonima crispa e Rinorea racemosa com 6,97\%, sendo que essas espécies estão entre as sete de maior VI do sítio.

Na metodologia de Souza (1990) - (Figura 5B), houve também a existência de três estratos de altura total. Observase no boxplot que o estrato médio (EM) abrangeu a maior quantidade de indivíduos (284 árvores), seguida pelos estratos: inferior (EI) e superior (ES), com 63 e 53 indivíduos, respectivamente. No estrato inferior a maior ocorrência das árvores delimitou-se entre o $1^{\circ}$ e $3^{\circ}$ quartil, na qual representam $50 \%$ do conjunto de dados das alturas, cujos valores dos limites: inferior e superior são consecutivamente $6,7 \mathrm{~m}$ e 12,2 m.

Nesse estrato, as alturas das espécies apresentaram uma assimetria positiva, isto é, o método sugere que os dados demonstram a mediana $(11 \mathrm{~m})$ com forte aptidão de concentrar as alturas nos valores mais elevados. Este comportamento foi também observado no estrato superior (ES), no entanto, com forte tendência de assimetria negativa, a exceção, foi o estrato médio (EM) que apresentou comportamento das distribuições dos dados das alturas de forma simétrica (Figura 5B).

Para o estrato médio, 142 indivíduos $(50 \%$ dos dados amplitude interquartil) revelaram alturas entre $14 \mathrm{~m}$ a $18 \mathrm{~m}$ (Figura 5B), os quais a Ecclinusa guianensis apresentou a maior densidade absoluta (29 ind.ha ${ }^{-1}$ ), juntamente com a espécie Cordia tetrandra (17 ind.ha $\left.{ }^{-1}\right)$. Observa-se que estas espécies também constituíram assim como a Rinorea racemosa, uma satisfatória distribuição do perfil vertical da comunidade estudada.
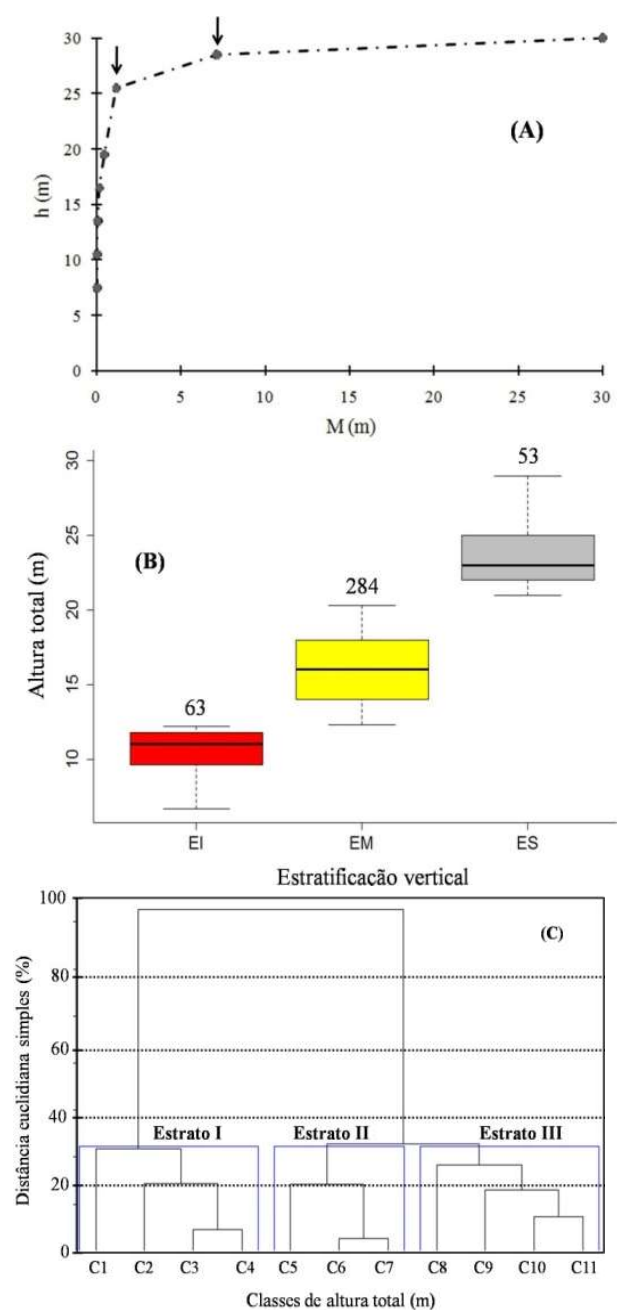

Figura 5.Representação do perfil vertical da floresta por meio de diferentes abordagens metodológicas. Legenda: (A) - Método de Sanquetta (1995); (B) - Método de Souza (1990); e (C) - Método de Souza et al. (2003). $\mathrm{h}$ - altura total; $\mathrm{M}$ - representa a média cumulativa parcial da atura a partir de maior valor de $h$.

Figure 5. Representation of the vertical profile of the forest through different methodological approaches. Caption: (A) - Sanquetta Method (1995); (B) - Souza method (1990); and (C) - Method of Souza et al. (2003).h - total height; M - represents the partial cumulative mean of the height from the highest value of $h$. 
A menor densidade de indivíduos foi verifica no estrato superior (ES), possuindo aproximadamente 27 árvores (50\%) com altura entre 22 a $25 \mathrm{~m}$, cujo limite superior é de 30 metros e o inferior de 21 metros (Figura 5B). Este estrato, apesar de possuir baixos quantitativos de indivíduos, foi que apresentou a maior concentração de árvores no dossel da floresta, podendo algumas espécies serem consideradas como emergentes.
A metodologia de análise de agrupamento proposto por Souza et al. (2003), em que os dados de frequências dos indivíduos distribuídos em 11 classes de alturas gerada a priori, pela equação do Sturgues com intervalo de $2 \mathrm{~m}$ permitiu agrupar sequencialmente as classes de altura total (Figura 5C), sendo que a análise discriminante linear de Fisher evidenciou que $99,00 \%$ delas foram corretamente classificadas (Tabela 3 ).

Tabela 3. A análise discriminante mostrando as porcentagens de classificações corretas (\%) e as probabilidades ( $p$ ) de classificações das alturas nos estratos formados.

Table 3. The discriminant analysis showing the percentages of correct classifications $(\%)$ and the probabilities $(p)$ of classifications of the heights in the strata formed.

\begin{tabular}{|c|c|c|c|c|c|c|}
\hline \multirow[b]{2}{*}{ Estrato } & \multicolumn{6}{|c|}{ Classificações } \\
\hline & Amplitude (m) & $\begin{array}{c}\mathrm{I} \\
(p=0,4096)\end{array}$ & $\begin{array}{c}\text { II } \\
(p=0,5079)\end{array}$ & $\begin{array}{c}\text { III } \\
(p=0,0797)\end{array}$ & Total & $\begin{array}{c}\text { Classificação correta } \\
(\%)\end{array}$ \\
\hline I & $6,7-15 \mathrm{~m}$ & 138,00 & 0,00 & 0,00 & 138,00 & 100,00 \\
\hline II & $15,1-21,3 \mathrm{~m}$ & 3,00 & 230 & 0,00 & 233,00 & 98,70 \\
\hline III & $21,4-29,7 \mathrm{~m}$ & 0,00 & 3,00 & 26,00 & 29,00 & 98,20 \\
\hline & Total & 141,00 & 233,00 & 26,00 & 400,00 & 99,00 \\
\hline
\end{tabular}

\section{DISCUSSÃO}

\subsection{Estrutura diamétrica, mortalidade e ingresso}

O resultado da estrutura diamétrica da comunidade e dos grupos ecológicos foram semelhante ao observado por Meyer (1952), Campos et al. 1983, Souza et al. (2006), Carvalho; Nascimento (2009), Alves-Júnior et al. (2010), ou seja, seguiu o padrão esperado para florestas inequiâneas na forma de "J" reverso, com maior frequência de indivíduos nas classes iniciais e diminuindo esta abundância nas classes sucessivas de forma exponencial negativa (ASSMANN, 1970).

Com relação aos valores obtidos pelo quociente "q" nas classes diamétricas sendo superior ao "q" médio tanto em nível de comunidade quanto da população (Figura 2 e 3), tal fato se configura um problema estrutural, visto que determinadas espécies apresentaram baixo nível de regeneração na área, implicando em uma dificuldade para permanecer na vegetação em razão de haver desequilíbrio entre a taxa de recrutamento e mortalidade. Carvalho; Nascimento (2009) reportam que este comportamento pode comprometer o equilíbrio estrutural da floresta em razão da ausência de novos indivíduos que venham substituir as árvores senescentes no futuro.

O padrão da curva de distribuição dos diâmetros por grupo sucessional sugere que o ambiente sofreu pequeno distúrbio, sendo em sua maioria relacionados a quedas naturais de certas espécies. Assim, verificamos que a taxa de recrutamento não compensou a perda de algumas árvores entre as classes, sendo evidenciado pela representação da taxa superior de mortalidade em relação à de recrutamento (ingresso), indicando que houve um balanço negativo no número de indivíduos no período de remedição.

Os valores da taxa de mortalidade (M\%) e ingresso ( $\mathrm{In} \%)$ para a área estudada contrastam com outros estudos realizados na Amazônia, como por exemplo, por Higuchi et al. (2004) que encontraram 0,7\% de (M) e (In), e por Colpini et al. (2010) que também encontraram valores inferiores de $\mathrm{M}=0,78 \%$ e In $=0,30 \%$ em comparação aos dados desta pesquisa. A explicação para a diferença nos resultados entre os trabalhos pode ser atribuída às características fisionômicas de cada vegetação, bem como fatores intrínsecos dessas florestas em termos de composição florística, grau de competição, ocorrência de distúrbios, e, sobretudo período de monitoramento (Cubas et al. 2016).
Os resultados observados na Figura 2, a qual há predominância de indivíduos jovens (DAP $<50 \mathrm{~cm}$ ) justificam a tese que o ambiente tenha sofrido severas perturbações no passado, demonstrando a necessidade de ações que venham conservar o ambiente (e.g. medidas silviculturais como enriquecimento de clareiras) para manter sua capacidade de resiliência, e consequentemente possam assegurar a uma estrutura diamétrica balanceada.

As variações dos valores de " $q$ " entre as classes diamétricas verificado tanto para a comunidade como pelos grupos sucessionais, indicam que as mudanças ocorridas durante o intervalo de um ano estão associadas aos processos ecológicos intrínseco de cada espécie no que tange a competição por recursos e pela própria ação natural nas quedas de árvores como evidenciado in locu, na qual possibilitou a entrada de mais luz solar no interior da mata, ajudando paulatinamente no crescimento e no ingresso de novos indivíduos que vai da menor para as maiores classes de diâmetro. Silva-Júnior (2004) corrobora com esta afirmação, a qual explica que as variações no quociente " q", entre as classes diamétricas, indicam taxas de recrutamento e mortalidade variáveis, isto é, relacionados com o próprio processo de dinâmica natural da fitocenose em estudo.

Alves-Júnior et al. (2010) avaliaram a distribuição diamétrica em um fragmento de Floresta Ombrófila Aberta em Pernambuco e constataram que mesmo apresentando a curva na forma de "J" reverso, a vegetação não revelou uma estrutura balanceada dos diâmetros. Os autores associaram este comportamento à forte influência das ações antrópicas (e.g. exploração madeireira) no passado que modificaram a estrutura da floresta culminando em uma estrutura rígida no atual processo de sucessão secundária do fragmento estudado.

Os resultados encontrados por esses autores reforçam os dados da presente pesquisa, e ainda permiti inferir que para possibilitar que floresta possa ser submetida a um sistema de manejo sustentável no futuro é fundamental a priori, adotar medidas conservacionista a médio e longo prazo até que a vegetação esteja em equilíbrio, para que, assim, não se comprometa espécies com déficit de indivíduos. 
Tabela 4. Incremento periódico médio anual (2016-2107) em diâmetro (IPAd-méd.) e em área basal (IPAG-méd.) para todas as espécies em seus respectivos grupos ecológicos.

Table 4. Average annual periodical increment (2016-2107) in diameter (IPAd-méd.) and in basal area (IPAG-méd.) for all species in their respective ecological groups.

\begin{tabular}{|c|c|c|c|c|c|c|}
\hline GE & Espécie & $\mathrm{N} / \mathrm{ha}$ & IPAd & IPA $_{d}$-méd./DP & $\mathrm{IPA}_{\mathrm{G}}$ & IPA $_{G}$-méd./DP \\
\hline \multirow{9}{*}{ 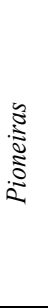 } & Albizia niopoides (Bentham) Burkart & 1,00 & 0,63 & & 0,0020 & \multirow{9}{*}{$0,0095 \pm 0,0084$} \\
\hline & Eugenia muricata DC. & 15,00 & 0,32 & & 0,0216 & \\
\hline & Eugenia sp. L. & 2,00 & 0,50 & & 0,0021 & \\
\hline & Genipa americana $\mathrm{L}$. & 2,00 & 0,29 & & 0,0017 & \\
\hline & Humiria balsamifera Aubl. & 7,00 & 0,47 & $0,4322 \pm 0,1309$ & 0,0205 & \\
\hline & Inga paraensis Ducke & 5,00 & 0,25 & & 0,0054 & \\
\hline & Jacaranda copaia (Aubl.) D. Don & 11,00 & 0,38 & & 0,0195 & \\
\hline & Tapirira guianensis Aubl. & 3,00 & 0,58 & & 0,0071 & \\
\hline & Zanthoxylum rhoifolium Lam. & 2,00 & 0,47 & & 0,0060 & \\
\hline \multirow{8}{*}{ 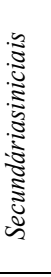 } & Brosimum acutifolium Huber & 1,00 & 0,21 & \multirow{8}{*}{$0,5588 \pm 0,3240$} & 0,0011 & \multirow{8}{*}{$0,0082 \pm 0,0121$} \\
\hline & Candolleodendron sp. R.S. Cowan & 1,00 & 0,63 & & 0,0105 & \\
\hline & Coussarea paniculata (Vahl) Standl. & 4,00 & 0,30 & & 0,0044 & \\
\hline & Inga alba $(\mathrm{Sw})$ Willd. & 2,00 & 1,28 & & 0,0050 & \\
\hline & Miconia regelii Cogn. & 2,00 & 0,54 & & 0,0030 & \\
\hline & Platonia insignis Mart. & 1,00 & 0,57 & & 0,0014 & \\
\hline & Rinorea racemosa (Mart.) Kuntze & 24,00 & 0,52 & & 0,0374 & \\
\hline & Siparuna decipiens (Tul.) A.DC. & 2,00 & 0,42 & & 0,0030 & \\
\hline \multirow{42}{*}{ 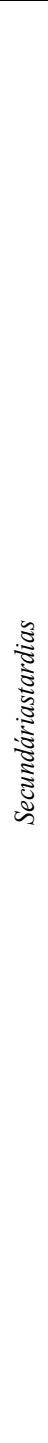 } & Ecclinusa guianensis Eyma & 50,00 & 0,47 & \multirow{42}{*}{$0,3607 \pm 0,1729$} & 0,0850 & \multirow{42}{*}{$0,0093 \pm 0,0145$} \\
\hline & Cordia tetrandra Aubl. & 39,00 & 0,35 & & 0,0309 & \\
\hline & Aspidosperma exalatum Monach. & 1,00 & 0,20 & & 0,0041 & \\
\hline & Couma guianensis Aubl. & 2,00 & 0,68 & & 0,0034 & \\
\hline & Parahancornia amapa (Huber) Ducke & 13,00 & 0,34 & & 0,0235 & \\
\hline & Protium decandrum (Aubl.) Marchand & 26,00 & 0,32 & & 0,0248 & \\
\hline & Protium neglectum Swart & 7,00 & 0,29 & & 0,0043 & \\
\hline & Protium sagotianum Marchand & 11,00 & 0,29 & & 0,0076 & \\
\hline & Goupia glabra Aubl. & 6,00 & 0,59 & & 0,0143 & \\
\hline & Byrsonima crispa Juss. & 24,00 & 0,36 & & 0,0366 & \\
\hline & Eschweilera longipes (Poit.) Miers. & 11,00 & 0,37 & & 0,0144 & \\
\hline & Osteophloeum platyspermum (Spruce ex A. DC.) & 16,00 & 0,29 & & 0,0128 & \\
\hline & Parinari excelsa Sabine & 5,00 & 0,30 & & 0,0062 & \\
\hline & Licania egleri Prance & 5,00 & 0,45 & & 0,0062 & \\
\hline & Virola michelii Heckel & 8,00 & 0,39 & & 0,0094 & \\
\hline & Manilkara paraensis (Huber) Standl. & 2,00 & 0,19 & & 0,0013 & \\
\hline & Sacoglottis guianensis Benth. & 7,00 & 0,33 & & 0,0141 & \\
\hline & Vochysia haenkeana Mart. & 3,00 & 0,27 & & 0,0030 & \\
\hline & Qualea albiflora Varm. & 3,00 & 0,34 & & 0,0059 & \\
\hline & Ocotea amazonica (Meisn.) Mez & 11,00 & 0,29 & & 0,0093 & \\
\hline & Aniba ferrea Kubitzki & 4,00 & 0,28 & & 0,0053 & \\
\hline & Aiouea grandifolia van der Werff & 4,00 & 0,22 & & 0,0024 & \\
\hline & Terminalia obovata Steud. & 1,00 & 0,22 & & 0,0005 & \\
\hline & Piptadenia gonoacantha (Mart.) J.F.Macbr. & 1,00 & 0,15 & & 0,0008 & \\
\hline & Alexa grandiflora Ducke & 2,00 & 0,11 & & 0,0010 & \\
\hline & Bowdichia sp. Kunth & 10,00 & 0,25 & & 0,0111 & \\
\hline & Lecythis lurida (Miers) S.A. Mori & 2,00 & 0,73 & & 0,0111 & \\
\hline & Mezilaurus synandra (Mez.) Kosterm. & 2,00 & 0,19 & & 0,0007 & \\
\hline & Iryanthera macrophylla (Benth.) Warb. & 5,00 & 0,35 & & 0,0051 & \\
\hline & Licania heteromorpha Benth. & 5,00 & 0,45 & & 0,0062 & \\
\hline & Ocotea fragrantissima Ducke & 3,00 & 0,86 & & 0,0068 & \\
\hline & Pouteria reticulata (Engl.) Eyma & 1,00 & 0,29 & & 0,0015 & \\
\hline & Couepia excelsa Ducke & 1,00 & 0,31 & & 0,0009 & \\
\hline & Ocotea guianensis Aubl. & 1,00 & 0,85 & & 0,0030 & \\
\hline & Endopleura uchi (Huber) Cuatrec. & 2,00 & 0,33 & & 0,0039 & \\
\hline & Ocotea argyrophylla Ducke & 2,00 & 0,31 & & 0,0009 & \\
\hline & Ocotea rubra Mez. & 4,00 & 0,33 & & 0,0029 & \\
\hline & Ocotea nusiana (Miq.) Kosterm & 7,00 & 0,31 & & 0,0059 & \\
\hline & Swartzia racemosa Benth. & 2,00 & 0,52 & & 0,0021 & \\
\hline & Licania heteromorpha Benth. & 1,00 & 0,22 & & 0,0007 & \\
\hline & Pouteria gongrijpii Eyma & 1,00 & 0,57 & & 0,0013 & \\
\hline & Pithecolobium racemosum Ducke & 1,00 & 0,19 & & 0,0013 & \\
\hline
\end{tabular}

em que: (N/ha) - números de indivíduos amostrais, GE - Grupo Ecológico e DP - Desvio Padrão.

É importante enfatizar que embora tenha ocorrido uma perda de indivíduos arbóreos de 2016 para 2017 (nove árvores no total), não houve redução da área basal do povoamento, sendo que na primeira avaliação era de $18,05 \mathrm{~m}^{2} / \mathrm{ha}$ e na segunda foi de 18,60 $\mathrm{m}^{2} / \mathrm{ha}$. Este resultado pode ser explicado pelas diferenças de crescimento dos diferentes grupos de espécies presente na fitocenose (Tabela 4) em que as espécies heliófitas (duráveis e efêmeras) crescem mais rapidamente em altura do que em diâmetro, produzindo teores moderados de material lenhoso em comparação as demais espécies de sucessão avançada (WHITMORE, 1990). 
Nesses termos, pode-se afirmar que pelas condições do meio (algumas clareiras naturais) e por existir na área maior representatividade de espécies pertencentes ao grupo das secundárias tardias, provavelmente, isso tenha gerado um ambiente favorável para este grupo, assim como aos demais, sendo que para as tardias foi demonstrado um crescimento em média de $0,36 \mathrm{~cm}^{2} \cdot \mathrm{ano}^{-1}$. Este resultado é compatível com o demonstrado por Oliveira (1995) que constatou que as espécies heliófitas duráveis (tardias) em uma floresta secundária no Pará, revelaram crescimento periódico anual em diâmetro, com média de $0,45 \mathrm{~cm} \cdot \mathrm{ano}^{-1}$.

A abordagem da estrutura diamétrica em nível de espécie considerando grupos sucessionais é uma alternativa de melhor compreender sobre o comportamento autoecológico e sinecológico da flora, e a partir disso, ter informações que possam levar a balizar tomadas de decisões no âmbito do manejo e da silvicultura em florestas tropicais. Na concepção de Paula et al. (2004) a separação das espécies em grupos ecológicos é uma maneira de possibilitar o manuseio do grande número de espécies da flora tropical, mediante seu agrupamento por funções semelhantes de acordo com suas exigências.

Nesse contexto, a explicação da "instabilidade" na estrutura diamétrica revelada pelas espécies pioneiras (Figura 2) pode estar associada com um reflexo do próprio comportamento ecológico desse grupo. Esta ideia é reforçada por Schaaf et al. (2006), as quais reportam que os indivíduos jovens desse grupo ecológico investem mais energia em altura do que em DAP na tentativa de ser manterem na comunidade, pois é fundamental chegar no dossel onde é mais favorável. Por esse motivo, se ver muitos indivíduos nas classes iniciais, enquanto que são baixos os números daqueles que conseguem chegar à maturidade (classes finais de diâmetro).

Considerando as análises das espécies individualmente, foi observado que a estrutura diamétrica difere relativamente de uma espécie para outra. A Cordia tetranda, por exemplo, apresentou tanto em 2016 como em 2017, diferentes valores para o quociente "q", evidenciando grande concentração de indivíduos em apenas uma classe (Figura 3). Já as espécies Protium decandrum e Rinorea racemosa apresentaram baixos valores de indivíduos nas menores classes diamétricas, fato que pode no futuro comprometer a regularidade estrutural das mesmas na área. Nesses termos, Aparício et al. (2014) esclarecem que a garantia da permanência de determinada espécie em uma floresta é função direta do número de indivíduos e da distribuição nas classes de tamanho, baseados no diâmetro ou na altura.

É importante salientar, que na prática os resultados sugerem que medidas buscando a estabilidade da estrutura diamétrica por longo prazo devem urgentemente ser adotadas, visando condicionar o caminho para a maturidade da vegetação. Por outro lado, novas pesquisas também devem ser adicionadas a esta a fim de englobar um maior tempo de monitoramento sobre a dinâmica da estrutura das espécies do ecossistema florestal estudado.

\subsection{Estrutura vertical}

Considerando que na comunidade prevaleceram as espécies pertencem ao grupo das secundárias tardias, pode-se inferir que o perfil vertical apresentado está associado ao comportamento ecológico das árvores deste grupo, ou seja, espécies com características de rápido crescimento (heliófilas duráveis) que se beneficiam das clareiras para se estabelecerem e se desenvolverem no ambiente. De acordo com Whitmore (1990) as espécies heliófitas duráveis apresentam como principais características a dominância do povoamento depois que as efêmeras desaparecem, acrescentado de ótimo incremento diamétrico (aproximadamente de 1,0 a $2,5 \mathrm{~cm}$ ) por ano e rápido crescimento em altura, principalmente se ocorrer uma abertura no dossel da floresta.

Das cinco espécies que mais se destacaram no estrato inferior (I) citadas no método de Sanquetta (1995), apenas Cordia tetrandra, Rinorea racemosa e Byrsonima crispa apresentaram indivíduos no estrato médio (II) de altura (20,1 a $25 \mathrm{~m}$ ). E destas, somente a Cordiaetrandra obteve árvores acima de $25 \mathrm{~m}$ (estrato III), logo, podemos afirmar que esta espécie tem sua permanência assegurada na estrutura do maciço florestal, em razão de possui indivíduos com diferentes classes de tamanho nos diferentes estratos verticais da comunidade, possibilitando que as árvores possam amadurecer e se reproduzir, sendo fundamental para a manutenção da vegetação.

Do ponto de vista ecológico, as espécies desse grupo apresentaram características de crescimento vertical dominante da vegetação, isso provavelmente se deu conforme Gomes et al. (2004), pelas respostas dos diferentes nichos ecológicos que desempenham na floresta associados às repostas aos fatores bióticos e abióticos que interagem no ambiente. Assim, essas espécies são fundamentais para a manutenção do habitat no que tange as relações ecológicas que desempenho na vegetação, contribuindo no processo de dinâmica sucessional em que a floresta se encontra.

Sanquetta et al. (2002) caracterizaram o comportamento do perfil vertical em um fragmento de floresta ombrófila mista por meio do diagrama h-M, e também indicaram a existência de três estratos de altura, sendo que o estrato (III) $-\mathrm{Ht} \leq 23 \mathrm{~m}$; foi o que demostrou a maior percentagem de indivíduos $95 \%$. Esses dados corroboram com os resultados de estratificação da atual pesquisa, e revelam que esta metodologia pode ser perfeitamente indicada para novos estudos de descrição da estrutura vertical das florestas da Amazônia.

A possível explicação para a predisposição de agrupar a maior frequência dos indivíduos arbóreos no estrato médio de altura como evidenciado no método de Souza (1990), pode está relacionado ao próprio conjunto da amostra dos dados que pode variar dependendo da tipologia florestal estudada. Por outro lado, como ocorreu a tendência dos valores estarem concentrados ora acima (EI) e ora abaixo (ES), pode-se inferir que este método tem a aptidão de agrupar os indivíduos no estrato médio de altura, podendo ser evidenciado pela predominância dos mesmos no referido estrato. Curto et al. (2013) observaram este mesmo comportamento em uma floresta estacional semidecidual, em que os autores concluíram que este método apresenta tendências fortes em concentrar um maior número de indivíduos no estrato médio da floresta, dificultando as interpretações.

Com essa metodologia, a Cordia tetrandra foi a espécie que mais se destacou em número de indivíduos (15 plantas) no estrato inferior do sítio, seguida por Rinorea racemosa (7) e Ecclinusa guianensis (5), sendo que juntas representam $42,85 \%$ da frequência populacional neste perfil vertical. Este resultado reforça a posição sociológica demonstrada pela espécie $R$. racemosa na estrutura da floresta, cuja distribuição nos três estratos foi expressiva, sendo que isso pode ser interpretado como o reflexo do seu comportamento ecológico, 
haja vista que pertence ao grupo das secundárias iniciais dos quais de acordo com Budowski (1965) apresenta como principais características, uma ampla distribuição natural nos estratos que compõe a comunidade florestal, com destaque para um maior adensamento populacional no estrato inferior e médio de altura, em razão do seu rápido crescimento vertical com copas finas e bem distribuídas horizontalmente.

Com base nos dados da estrutura diamétrica aliados aos da estrutura vertical, podemos afirmar que a floresta é caracterizada por espécies arbóreas com dimensões mais finas e de menor porte no subdossel, pois a alta luminosidade devido às clareiras naturais estimulou o crescimento em altura sem grande investimento em diâmetro, com algumas exceções para aquelas árvores com DAP $>40 \mathrm{~cm}$, como é o caso da Ecclinusa guianensis, na qual necessita de crescimento diamétrico para manter o maior porte no dossel da fitocenose.

Ressalta-se que, embora tenha apresentado potencial de agrupar as alturas das árvores com certo grau de assimetria, o método de Souza (1990) é bastante difundido e empregado em estudos da caracterização vertical em florestas naturais no Brasil, visto sua fácil aplicação e flexibilidade em retratar a estratificação vertical tanto em nível de comunidade como de povoamento. Assim, os resultados aqui demonstrados por meio desta técnica foram úteis para fornecer informações importantes para a compreensão das características de cada espécie, sendo que a estrutura vertical caracterizada foi similar ao encontrado nos trabalhos de Pinto-Sobrinho et al. (2009) e Condé; Tonini (2013).

Por meio do método de Souza et al. (2003), a espécie Ecclinusa guianensis demostrou o maior valor de posição sociológica com 22 e 28 ind.ha $^{-1}(12,5 \%)$ distribuídos no

Tabela 5. Características dendrométricas após o emprego dos métodos de estratificação vertical em floresta densa de terra firme, Macapá, Amapá, Brasil.

Table 5. Dendrometric characteristics after the use of vertical stratification methods in dense terra firme forest, Macapá, Amapá, Brazil.

\begin{tabular}{|c|c|c|c|c|c|c|c|c|}
\hline Método & Estrato & Variável & $\mathrm{Ni}$ & Mín. & Med. & Máx. & DP & C.V (\%) \\
\hline \multirow{6}{*}{ A } & \multirow{2}{*}{ Inferior } & Altura (m) & \multirow{2}{*}{344} & 6,70 & 15,17 & 20,00 & 3,02 & 19,94 \\
\hline & & Diâmetro $(\mathrm{cm})$ & & 10,02 & 19,73 & 104,40 & 9,73 & 49,33 \\
\hline & \multirow{2}{*}{ Médio } & Altura (m) & \multirow{2}{*}{46} & 20,1 & 22,57 & 25 & 1,62 & 7,21 \\
\hline & & Diâmetro $(\mathrm{cm})$ & & 16,15 & 32,11 & 59,20 & 9,49 & 29,57 \\
\hline & \multirow{2}{*}{ Superior } & Altura (m) & \multirow{2}{*}{10} & 25,20 & 27,45 & 30,00 & 1,70 & 6,20 \\
\hline & & Diâmetro $(\mathrm{cm})$ & & 11,93 & 33,48 & 62,38 & 19,16 & 57,23 \\
\hline \multirow{6}{*}{ B } & \multirow{2}{*}{ Inferior } & Altura (m) & \multirow{2}{*}{63} & 6,70 & 10,46 & 12,20 & 1,45 & 13,86 \\
\hline & & Diâmetro $(\mathrm{cm})$ & & 10,02 & 14,73 & 28,32 & 4,92 & 33,42 \\
\hline & \multirow{2}{*}{ Médio } & Altura (m) & \multirow{2}{*}{284} & 12,30 & 16,27 & 20,30 & 2,18 & 13,42 \\
\hline & & Diâmetro $(\mathrm{cm})$ & & 10,02 & 20,86 & 104,40 & 10,14 & 48,61 \\
\hline & \multirow{2}{*}{ Superior } & Altura (m) & \multirow{2}{*}{53} & 21,00 & 23,62 & 30,00 & 2,43 & 10,28 \\
\hline & & Diâmetro $(\mathrm{cm})$ & & 11,93 & 32,95 & 62,38 & 11,59 & 35,20 \\
\hline \multirow{6}{*}{$\mathrm{C}$} & \multirow{2}{*}{ Inferior } & Altura (m) & \multirow{2}{*}{138} & 6,7 & 12,10 & 14,3 & 1,83 & 15,17 \\
\hline & & Diâmetro $(\mathrm{cm})$ & & 10,02 & 15,57 & 42,97 & 5,61 & 36,08 \\
\hline & \multirow{2}{*}{ Médio } & Altura (m) & \multirow{2}{*}{233} & 14,4 & 17,71 & 22,50 & 2,00 & 11,30 \\
\hline & & Diâmetro $(\mathrm{cm})$ & & 10,18 & 23,66 & 104,40 & 11,36 & 48,03 \\
\hline & \multirow{2}{*}{ Superior } & Altura (m) & \multirow{2}{*}{29} & 23,00 & 25,36 & 30,00 & 1,96 & 7,75 \\
\hline & & Diâmetro $(\mathrm{cm})$ & & 11,93 & 32,38 & 62,38 & 11,81 & 36,47 \\
\hline
\end{tabular}

Legenda: A - Sanquetta (1995); B - Souza (1990); C - Souza et al. (2003); Número de indivíduos (Ni); Valor mínimo (Mín.) e máximo (Máx.); Média aritmética - (Med.); Desvio padrão - (DP); e Coeficiente de variação (C.V).

\section{CONCLUSÕES}

Com base no monitoramento de um ano foi observado que a comunidade florestal não apresentou estrutura balanceada, estrato inferior (I) e médio (II), respectivamente. Por outro lado, no estrato superior (III) foram as espécies Parahancornia fasciculata (5 ind.ha- ${ }^{-1}$ ) e Jacaranda copaia $\left(5\right.$ ind.ha $\left.{ }^{-1}\right)$ as que predominaram revelando boa expressão de posição sociológica $(2,5 \%)$. Analisando o comportamento específico por espécie pelos métodos empregados, percebe-se que as oito plantas florestais de maior valor de importância registrada no inventário foram as que dominaram o perfil vertical da floresta.

Por serem as espécies mais representativas da vegetação, e levando em consideração suas características ecológicas em termos sucessionais, este resultado já era esperado. Assim, pode-se deduzir que essas espécies são essenciais para a sustentabilidade ambiental da comunidade arbórea analisada. Dessa forma, acrescenta-se que o número de estratos definidos em ambos as metodologias foram adequadas, pois conseguiram classificar a estrutura vertical da vegetação em consonância como padrão sucessional das espécies no sítio, com destaque para o método de Sanquetta (1995) que descreveu de forma mais satisfatória essa estrutura (Tabela 5).

Comparando os métodos observa-se que a metodologia proposta por Sanquetta, apresentou menores valores de coeficiente de variação (C.V) das alturas agrupadas entre os três estratos definidos, sendo, portanto, a metodologia que melhor descreveu o perfil vertical da floresta estudada. Também, chama-se atenção para o método de Souza et al. (2003), em virtude da boa classificação dos estratos da vegetação, bem como pelos valores reduzidos da estatística de dispersão (C.V) (Tabela 4).

pois há déficit de árvores nas classes diamétricas, apresentando problemas de regeneração. Desse modo, em virtude da baixa densidade de árvores, justifica-se a intervenção por meio de tratamentos silviculturais que auxilie a promover o aumento da sua regeneração natural na floresta e o crescimento das plantas mais jovens. 
Com relação aos grupos sucessionais, as interferências por clareiras naturais culminaram em modificações nas classes de tamanho das espécies dos grupos avaliados, indo da mais baixas alterações para as secundárias iniciais e tardias até a maior "instabilidade" de estrutura diamétrica para as pioneiras, sendo este aspecto por sua vez relacionado à autoecologia deste grupo sucessional, em que apresenta moderada produção de material lenhoso em diâmetro, fato esse esperado pelo alto grau de competição em florestas secundárias.

A floresta continua crescendo em área basal indicando claramente que ainda está evoluindo em busca de atingir seu estoque completo, ainda que a mortalidade tenha sido maior que o ingresso.

Os resultados da estrutura altimétrica e diamétrica demonstraram indicativos que as explorações antrópicas no passado juntamente com as ações de quedas naturais de algumas árvores alteraram o ambiente e a estrutura populacional das espécies, e como efeito a floresta encontrase em estágio de sucessão intermediária, revelando uma densidade elevada de indivíduos nas menores classes de diâmetros distribuídas nos diferentes estratos da vegetação.

\section{REFERÊNCIAS}

ALVES JÚNIOR, F. T.; FERREIRA, R. L. C.; SILVA, J. A. A.; MARANGON, L. C.; COSTA JÚNIOR, R. F.; SILVA, S. O. Utilização do quociente de DeLiocourt na avaliação da distribuição diamétrica em Fragmentos de Floresta Ombrófila Aberta em Pernambuco. Ciência Florestal, Santa Maria, v. 20, n. 2, p. 307-319, 2010. DOI: http://dx.doi.org/10.5902/198050981854

AMARAL, D. D.; VIEIRA, I. C. G.; ALMEIDA, S. S.; SALOMÃO, R. P.; SILVA, A. S. L.; JARDIM, M. A. G. Checklist da flora arbórea de remanescentes florestais da região metropolitana de Belém e valor histórico dos fragmentos, Pará, Brasil. Boletim Museu Paraense Emílio Goeldi, Ciências Naturais, Belém, v. 4, n. 3, p. 231-289, 2009.

AMARAL, R. C. C. Proposição de método multivariado de estratificação vertical em floresta natural. $2011.43 \mathrm{f}$. Dissertação (Mestrado em Biometria e Estatística Aplicada), Universidade Federal Rural de Pernambuco, Recife, 2011.

APARICIO, P. S.; SOTTA, E. D.; GUEDES, M. C.; APARÍCIO, W. C. D. S.; OLIVEIRA, L. P.; SOUZA, R. N. Níveis de regeneração natural em floresta de terra firme no Amapá Brasil. Revista Árvore, Viçosa, v. 38, n. 4, p. 699-710, 2014. DOI: http://dx.doi.org/10.1590/S010067622014000400013

ASSMANN, E. The principles of forest yield: studies in the organic production, structure, increment and yield of forest stands. Oxford: Pergamon Press, 1970. 506p.

BUDOWISK, G. Distribution of tropical american rain forest species in the light of successional processes. Turrialba, San José, v. 15, n. 1, p. 40-42, 1965.

CAMPOS, J. C. C.; RIBEIRO, J. C., COUTO, L. Emprego da distribuição diamétrica na determinação da intensidade de corte em matas naturais submetidas ao sistema de seleção. Revista Árvore, Viçosa, v. 7, n. 2, p. 110-122, 1983.

CARVALHO, F. A.; NASCIMENTO, M. T. Estrutura diamétrica da comunidade e das principais populações arbóreas de um remanescente de Floresta Atlântica Submontana (Silva Jardim-RJ, Brasil). Revista Árvore,
Viçosa, v. 33, n. 2, p. 327-337, 2009. DOI: http://dx.doi.org/10.1590/S0100-67622009000200014

COLPINI, C.; SILVA, V. S. M.; SOARES, T. S.; HIGUCHI, N.; TRAVAGIN, P.; ASSUMPÇÃO, J. V. L. Incremento, ingresso e mortalidade em uma floresta de contato ombrófila aberta/estacional em Mercelândia, Estado do Mato Grosso. Acta Amazonica, Manaus, v. 40, n. 3, p. 549-556, 2010. DOI: http://dx.doi.org/10.1590/S004459672010000300014

CONDÉ, T. M.; TONINI, H. Fitossociologia de uma Floresta Ombrófila Densa na Amazônia Setentrional, Roraima, Brasil. Acta Amazonica, Manaus, v. 43, n. 3, p. 247-260, 2013. DOI: http://dx.doi.org/10.1590/S004459672013000300002

CUBAS, R.; WATZLAWICK, L. F.; FIGUEIREDO-FILHO, A. Incremento, ingresso, mortalidade em um remanescente de Floresta Ombrófila Mista em três Barras - SC. Ciência Florestal, Santa Maria, v. 26, n. 3, p. 889900, 2016.2 DOI: http://dx.doi.org/10.5902/1980509824216

CURTO, R. D. A.; SILVA, G. F.; PEZZOPANE, J. E. M.; CHICHORRO, J. F.; MÔRA, R. Métodos de estratificação vertical em Floresta Estacional Semidecidual. Ciência Florestal, Santa Maria, v. 23, n. 4, p. 643-654, 2013. DOI: http://dx.doi.org/10.5902/1980509810538

DE LIOCOURT, F. De l'amenagement dessapinières. Tradução Maria Nygren. Société Forestière de FrancheComté et Belfort, Bulletin trimestriel, p. 396-409, 1898.

FELFILI, J. M.; REZENDE, R. P. Conceitos e métodos em fitossociologia. Brasília: Ed da UNB, 2003. v. 5. 68 p.

FIGUEIRO-FILHO, A.; DIAS, A. N.; STEPKA, T. F.; SAWCZUK, A. R. Crescimento, mortalidade, ingresso e distribuição diamétrica em floresta ombrófila mista. Floresta, Curitiba, v. 40, n. 4, p. 763-776, 2010. DOI: http://dx.doi.org/10.5380/rf.v40i4.20328

GOMES, A. P. C.; SOUZA, A. L.; MEIRANETO, J. A. Alteração estrutural de uma área florestal explorada convencionalmente na bacia do Paraíba do Sul, MG, nos domínios de Floresta Atlântica. Revista Árvore, Viçosa, v. 28 , n. 3, p. 407-417, 2004. DOI: http://dx.doi.org/10.1590/S0100-67622004000300012

HIGUCHI, N.; CHAMBERS, J. Q.; SANTOS, J.; RIBEIRO, R. J.; PINTO, A. C. M.; SILVA, R. P.; ROCHA, R. M.; TRIBUZY, E. S. Carbon balance and dynamics of primary vegetation in the Central Amazon. Floresta, Curitiba, v. 34, n. 3, p. 377-384, 2004. DOI: http://dx.doi.org/10.5380/rf.v34i3

IEPA INSTITUTO DE PESQUISAS CIENTÍFICAS E TECNOLOGICAS ESTADO DO AMAPÁ. Macrodiagnóstico do estado do Amapá, primeira aproximação do ZEE. Amapá: 2008. 139p.

JARDIM, F. C. S. Mortalidade e crescimento na floresta equatorial de terra firme. Museu Paraense Emílio Goeldi, Série Botânica, Belém, v. 6, n. 2, p. 227-234, 1990.

LIMA, R. B.; APARACIO, P. S.; SILVA, W. C.; SILVA, D. A. S.; GUEDES, A. C. L. Emprego da distribuição diamétrica na predição do estado de perturbação em Floresta de Várzea, Macapá-AP. Enciclopédia Biosfera, Goiânia, v. 9, n. 16; p. 1-11, 2013.

MACHADO, S. A.; FIGUEIREDO-FILHO, A. Dendrometria. 3. ed. Guapavara: Universidade Estadual do Centro-Oeste, 2014. 316p. 
MEYER, H. A. Structure, growth, and drain in balanced uneven-aged forests. Journal of Forestry, Washington, v. 50, p. 85-92, 1952.

OLIVEIRA, L. C. Dinâmica de crescimento e regeneração natural de uma floresta secundária no Estado do Pará. 1995. 69 f. Dissertação (Mestrado) - Universidade Federal do Pará, Belém, 1995.

OLIVEIRA, L. C.; COUTO, H. T. Z.; SILVA, J. N. M.; CARVALHO, J. O. P. Efeito da exploração de madeira e tratamentos silviculturais na composição florística e diversidade de espécies em uma área de 136 ha na Floresta Nacional do Tapajós, Belterra, Pará. Scientia Forestalis, Piracicaba, n. 69, p. 62-76, 2005.

PAULA, A.; PAULA, A.; SILVA, A. F.; MARCO JÚNIOR, P.; SANTOS, F. A. M.; SOUZA, A. L. Sucessão ecológica da vegetação arbórea em uma floresta estacional semidecidual, Viçosa, MG, Brasil. Acta Botânica Brasílica, São Paulo, v. 18, n. 3, p. 407-423, 2004. DOI: http://dx.doi.org/10.1590/S0102-33062004000300002

PINTO-SOBRINHO, F. D. A. P.; CHRISTO, A. G.; GUEDES-BRUNI, R. R.; SILVA, A. F. Composição florística e estrutura de um Fragmento de Floresta Estacional Semidecidual Aluvial em Viçosa (MG). Floresta, Curitiba, v. 39, n. 4, 2009. DOI: http://dx.doi.org/10.5380/rf.v39i4.16314

R CORE TEAM. R: a language and environment for statistical computing. R Foundation for Statistical Computing. Vienna, 2015. Disponível em: $<$ http://www.R-project.org/>. Acesso em: 15 maio 2016.

REIS, L. P.; RUSCHEL, A. R.; SILVA, J. N. M.; REIS, P. C. M.; CARVALHO, J. O. P.; SOARES, M. H. M. Dinâmica da distribuição diamétrica de algumas espécies de Sapotaceae após exploração florestal na Amazônia Oriental. Revista de Ciências Agrárias, Belém, v. 57, n. 3, p. 234-243, 2014

SANQUETA, C. R. Análise da estrutura vertical de florestas através do diagrama h-M. Ciência Florestal, Santa Maria, v. 5, n. 1, p. 55-68, 1995. DOI: http://dx.doi.org/10.5902/19805098310

SANQUETTA, C. R., PIZATTO, W.; NETTO, S. P.; FIGUEIREDO FILHO, A.; EISFELD, R. D. L. Estrutura vertical de um Fragmento de Floresta Ombrófila Mista no Centro-Sul do Paraná. Floresta, Curitiba, v. 32, n. 2, 2002. DOI: http://dx.doi.org/10.5380/rf.v32i2.2291

SANTOS, R. O.; LIMA, R. C.; LIMA, R. B.; APARÍCIO, P. S.; ABREU, J. C. Florística e estrutura de uma comunidade arbórea na floresta estadual do Amapá, Amazônia Oriental, Brasil. Nativa, Sinop, v. 5, n. esp., p. 529-539, 2017. DOI: http://dx.doi.org/10.5935/23187670.v05nespa11
SANTOS, R. O.; SOARES, R. N.; SOUZA, DANTAS, B.; ABREU, J. C.; LIMA, R. B. Processos amostrais para estimativa de parâmetros estruturais de uma floresta estuáriana no estado do Amapá. Nativa, Sinop, v. 4, n. 5, p. 308-316, 2016. DOI: http://dx.doi.org/10.14583/23187670.v04n05a07

SCHAAF, L. B.; FIGUEIREDO-FILHO, A.; GALVÃO, F.; SANQUETTA, C. R. Alteração na estrutura diamétrica de uma floresta ombrófila mista no período entre 1979 e 2000. Revista Árvore, Viçosa, v. 30, n. 2, p. 283-295, 2006. DOI: http://dx.doi.org/10.1590/S010067622006000200016

SCOLFORO, J. R.; OLIVEIRA, A. D. S.; SILVA, S. T. O manejo da vegetação nativa através de corte seletivo. In: CURSO DE MANEJO FLORESTAL SUSTENTÁVEL, 1997, Curitiba. Tópicos de manejo florestal sustentável. Colombo: EMBRAPA-CNPF, 1997. 253p.

SILVA-JÚNIOR, M. C. Fitossociologia e estrutura diamétrica da Mata de Galeria da Taquara na Reserva Ecológica do IBGE, DF. Revista Árvore, Viçosa, v. 28, n. 3, p. 419428, 2004. DOI: http://dx.doi.org/10.1590/S010067622004000300013

SILVA, K. E.; MARTINS, S. V.; RIBEIRO, C. A. A. S.; SANTOS, N. T.; AZEVEDO, C. P. Structure of 15 hectares permanent plotsof terra firme dense forest in Central Amazon. Revista Árvore, Viçosa, v. 40, n. 4, p. 603-615, 2016. DOI: http://dx.doi.org/10.1590/010067622016000400004

SOUZA, A. L. Estrutura, dinâmica e manejo de florestas tropicais. Viçosa: UFV, 1990. 122 p. (Notas de aula).

SOUZA, D. R. D.; SOUZA, A. L. D., LEITE, H. G., YARED, J. A. G. E. C. Análise estrutural em Floresta Ombrófila Densa de terra firme não explorada, Amazônia Oriental. Revista Árvore, Viçosa, v. 30, n. 1, p. 75-87, 2006. DOI: http://dx.doi.org/10.1590/S0100-67622006000100007

SOUZA, D. R.; SOUZA, A. L. Estratificação vertical em Floresta Ombrófila Densa de terra firme não explorada, Amazônia Oriental. Revista Árvore, Viçosa, v. 28, n. 5, p. 691-698, 2004. DOI: http://dx.doi.org/10.1590/S010067622004000500008

SOUZA, D. R.; SOUZA, A. L.; GAMA, J. R. V.; LEITE, H. G. Emprego de análise multivariada para estratificação vertical de florestas inequiâneas. Revista Árvore, Viçosa, v. 27, n. 1 , p. 59-63, 2003. DOI: http://dx.doi.org/10.1590/S0100-67622003000100008

WHITMORE, T. C. Tropical Rain Forest dynamics and its implications for management. In: GOMESPOMPA, A.; WHITMORE, T. C.; HADLEY, M. Rain forest regeneration and management. Paris: UNESCO/The Part Eenon Publishing Group, 1990. p. 67-89. 